\title{
El nacimiento de un frente estético contra el franquismo: entre la abstracción y la figuración
}

\section{The birth of an aesthetic antifrancoist front: between abstraction and figuration}

\author{
Noemi De Haro García \\ Grupo de Cultura Visual Contemporánea \\ Departamento de Historia y Teoría del Arte. Universidad Autónoma de Madrid \\ noemi_deharo@yahoo.es
}

Recibido: 27 de diciembre de 2010

Aprobado: 25 de abril de 2011

\begin{abstract}
Resumen
En este artículo se analiza la aparición de las principales corrientes artísticas que, a partir de finales de los años cincuenta, hicieron inteligible una vía estética, social y política gracias a la cual tomaba cuerpo una alternativa al discurso estético oficial del franquismo en España, representado por el informalismo. A través del estudio de su desarrollo histórico, se muestran los vínculos existentes entre las principales corrientes plásticas del antifranquismo: la abstracción geométrica y el realismo social, que suelen estudiarse y presentarse por separado. Esto permite entender mejor la colaboración que, muy pronto, se estableció entre sus miembros para constituir un frente estético contra el franquismo. Se sostiene que todas estas propuestas tuvieron un sentido mucho más complejo y rico, éste se hace patente cuando se las analiza como elementos fundamentales en la configuración de los marcos culturales del movimiento social antifraquista que se desarrolló en España a partir de los años cincuenta.
\end{abstract}

Palabras Clave: Movimientos sociales, arte comprometido, realismo social, informalismo, abstracción geométrica.

Haro García, Noemí de 2011: El nacimiento de un frente estético contra el franquismo: entre la abstracción y la figuración. Arte, Individuo y Sociedad, 23 (2), 85-96

\begin{abstract}
This paper analyzes the appearance of the principal artistic movements that opened an aesthetic, social and political way against francoism in the Spain of the fifties. This meant an alternative to the aesthetic official discourse of the regime in Spain, represented by informalism. The study of the historical development of the former movements intends to show the links that existed between the main antifrancoist artistic activities: geometric abstraction and social realism, which are usually studied and presented separately. This allows a better understanding of the early collaboration of its members to build an aesthetic front against francoism. It is stated here that these initiatives had a richer and more complex sense, which reveals itself when they are analyzed as essential elements in the construction of the cultural frames of the antifrancoist social movements that began their struggle in the Spain of the fifties. Key Words: Social movements, engaged art, social realism, informalism, geometrical abstraction.
\end{abstract}

Haro García, Noemí de 2011: The birth of an aesthetic antifrancoist front: between abstraction and figuration. Arte, Individuo y Sociedad, 23 (2), 85-96

Sumario: 1. Un arte moderno para un país diferente, 2. Primeras iniciativas de arte social, 3. La figuración se extiende. Referencias 
Este artículo recoge resultados de la investigación vinculada al proyecto "Arte y artistas españoles dentro y fuera de la dictadura franquista" (HAR 2008-00744), financiado por el MICINN.

\section{Un arte moderno para un país diferente}

El periodo inmediatamente posterior a la Guerra Civil supuso para España unos duros años de autarquía en los que el país se cerró en sí mismo apoyado por el fascismo y el nazismo. En 1945, con la derrota de los regímenes italiano y alemán en la II Guerra Mundial, la situación se hizo insostenible. Si la dictadura quería continuar se tenía que incorporar a un panorama más amplio y para ello no podía seguir siendo vista como reducto de las ideas de los derrotados en el conflicto mundial. Se inició entonces un proceso que, como han analizado investigadores como Domínguez Perela (1990), estuvo orientado hacia la integración de la práctica política española en el resto del mundo capitalista occidental. Esto suponía la urgente introducción de nuevas ideas y actuaciones, lo cual se vio facilitado por el hecho de que, progresivamente, los valores del Movimiento Nacional habían quedado reducidos a algo meramente referencial. Se llevaron a cabo una serie de reformas en el Gobierno que provocaron cambios en la economía y en el modo en que el país se presentó al exterior. En el interior esto se tradujo en el comienzo de una época de desarrollo económico en la que una parte de la población empezó a ver mejoradas sus condiciones de vida. De cara al exterior se empezó a hacer hincapié, entre otras cosas, en que España había sido uno de los primeros países en luchar contra el comunismo, lo cual facilitaba las relaciones con Estados Unidos que eran muy favorables al acercamiento ya que así podían contar con la situación militar estratégica de la península.

El mundo había de olvidar el origen fascista y violento de la dictadura para entenderla como la forma de gobierno que necesitaba un país que presentaba ciertas "peculiaridades". No se trataba de algo tan difícil ya que la singularidad española formaba parte de los tópicos existentes acerca del país. Esto, aderezado con el correspondiente discurso sobre la naturaleza independiente e individual del arte, acabó proporcionando las herramientas que llevaron al franquismo a dar forma a una política cultural con la que vaciar de contenido político la imagen del régimen en el exterior. Así, en la segunda mitad del siglo, la dictadura comenzó a apoyar una serie de actividades culturales que supusieron un cambio muy importante en la política artística oficial en relación con las estéticas más avanzadas. Según Miguel Cabañas $(1995,1996$ a y b), la primera estrategia de envergadura ideada en este sentido fue el plan de celebración de las bienales hispanoamericanas de arte (Fig.1). A través de ellas España pretendía mostrar su capacidad para abrir nuevos campos de influencia, organizando una estructura internacional en la que hacía las veces de mediadora entre el mundo occidental y los países latinoamericanos en virtud de una lengua y una cultura comunes. 


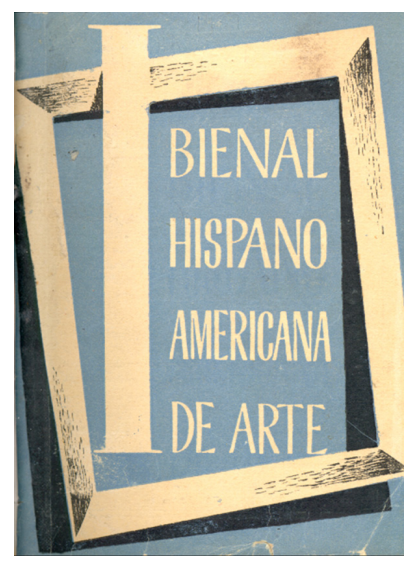

Figura 1. Cubierta del catálogo de la I Bienal Hispanoamericana de Arte, 1951

Al margen de que en dicho plan se trasluce una concepción de la relación entre España y dichos países con tintes coloniales, hay que hacer notar que a través de estos eventos se empezó a difundir también el mensaje de que, en España, no había dirigismo en lo referente a la estética y la cultura. Ya en la inauguración de la I Bienal Hispanoamericana de Arte, celebrada en 1951, Joaquín Ruiz Giménez afirmaba que el Estado no debía inmiscuirse en la creación artística debido a que la naturaleza del arte auténtico era la autonomía. El arte quedaba caracterizado así por sus vínculos directos con la verdad y la belleza, por su independencia total de lo contingente en general y de lo político en particular, ya que todo lo auténtico era definido como impolítico; en definitiva el arte era considerado "expresión libre del alma individual" (Ruiz, 1952, pág. 163). Pero detrás de tales palabras se encontraba una forma de control: aunque la dictadura afirmaba que se oponía a un arte del régimen propiamente dicho, al proclamarse garante de que arte y artistas expresaran su esencia en total libertad, el Estado se convertía en principal responsable a la hora de decidir en qué consistía dicha esencia, así como en juez de qué y quién la expresaba del modo adecuado.

El éxito llegó cuando los tópicos románticos y pintorescos sobre España que formaban parte del imaginario colectivo internacional se aderezaron con elementos relacionados con las corrientes artísticas extranjeras. Se trataba de una fórmula que venía a hacer realidad las recomendaciones de Ruiz Giménez a los artistas en su discurso de 1951: que vivieran el momento histórico sin dejar de respetar por ello unos valores nacionales propios. Su vehículo estético fue el informalismo de El Paso, auténtico elixir de expresionismo abstracto americano con sabor a veta brava. En sus inicios las cuestiones estéticas no formaban parte de los principios aglutinadores del grupo, ni tampoco "lo hispánico", pero eso no importaba demasiado: advirtiendo los puntos en común que el trabajo de estos artistas tenía con corrientes internacionales como la del expresionismo abstracto americano, Luis González Robles, comisario de las exposiciones oficiales en el extranjero, eligió a los representantes españoles de las bienales de Sâo Paulo y Venecia de entre los miembros de este grupo. Con el premio obtenido en la $29^{\text {a }}$ edición de la bienal veneciana, en 1958, les llegó la consagración definitiva a nivel internacional. Ya entonces los propios críticos vinculados a El 
Paso comenzaban a incorporar en sus presentaciones ciertas ideas que recordaban a aquéllas que Ruiz Giménez había expuesto en 1951. Como ejemplo cabe recordar el texto de Manuel Conde para la exposición Cuatro pintores y un escultor donde se hablaba de que uno de los objetivos del grupo era contribuir a "encauzar características particularmente españolas en una obra de alcance internacional" y sus componentes se declaraban "por un arte individual, dentro del signo de nuestra época" (Conde, 1958, citado en Calvo, 1985, pág. 425).

Tal y como ha estudiado Julián Díaz Sánchez (1998 y 2000), las características que se asociaban con la tradición de la escuela pictórica española se hallaron plasmadas en la abstracción de El Paso. Éstas servían no sólo para entender la abstracción informalista dentro del país -esto costó bastante trabajo a los sectores más tradicionalistas del arte español-, sino sobre todo para proyectarla en el exterior. Así, unos años más tarde, en la recopilación La pintura informalista en España a través de los críticos, cuyo texto aparecía redactado en tres idiomas - español, inglés y francés-, se hablaba de valores como la austeridad, la espiritualidad, la luz, la materia o el color de esta pintura y se reclamaba para sus creadores una filiación estrictamente española (Ainaud, et al., 1961).

\section{Primeras iniciativas de arte social}

Mientras sucedía todo esto, los crecientes contactos con el exterior favorecieron que se conocieran otras realidades que eran sensiblemente diferentes de la cotidianeidad española. Esto, en conjunción con las consecuencias que la política de estabilización tuvo en los sectores de la sociedad más desfavorecidos, generó una creciente sensación de incomodidad y descontento que desembocó en las primeras reacciones organizadas y efectivas contra el franquismo. El régimen no permaneció indiferente y respondió con la censura y la represión; pero el proceso tenía una difícil marcha atrás una vez que las primeras voces se habían atrevido a romper el silencio impuesto.

El antifranquismo contó con el apoyo, fundamental, del Partido Comunista Español (PCE) que había empezado a reorganizarse en la clandestinidad en 1953. La oposición tomó cuerpo en el movimiento obrero y en el mundo universitario que, a su vez, influyó en la organización de las actividades desarrolladas en el sector cultural. El cine y la literatura fueron los primeros campos en los que se manifestó el movimiento crítico desde las artes, que manifestaba un deseo imperioso de reflejar la realidad social y la condición humana con el fin de transformarlas; el deseo de que, gracias al arte, la sociedad mejorase sus condiciones de vida. Pronto esto encontraría su correlato en las artes plásticas. Frente a las aspiraciones espirituales y al carácter apolítico que el Estado reclamaba para un arte pensado para las elites, se abría una vía que partía de una visión explícitamente comprometida con todos los aspectos de la realidad, incluido el político. Muchos artistas pensaron que la mejor manera de lograr esto era conseguir que su trabajo estuviera al alcance de la sociedad, que éste formara parte de su día a día de un modo útil. Para ello habían de hacerse bien obras públicas, bien obras asequibles que formaran parte de la vida privada. Dos caminos estéticosfueron definiéndose, casi al mismo tiempo, como respuesta a dichos requerimientos de un arte inmerso en el tejido social: la abstracción geométrica y el realismo social. 
En el desarrollo de esta última corriente, la del realismo social, fue muy importante la figura de José García Ortega, responsable de la organización del PCE entre los artistas plásticos. Desde 1953 Ortega -como firmaba sus obras- acudía al Círculo de Bellas Artes, la Asociación de Dibujantes y la facultad de Bellas Artes de Madrid en busca de jóvenes artistas que incorporar a la causa antifranquista. Su capacidad de reunión y organización tuvo, como primer fruto, la exposición Tres pintores y un tema, celebrada en noviembre de 1956 en la galería Alfil de Madrid. Allí se colgaron las obras figurativas de este pintor junto con las de Pascual Palacios Tardez y José Ruiz Pernias; los temas de las mismas giraban en torno a la situación de los habitantes de los espacios degradados y marginados de las ciudades. Cada artista hacía una breve declaración en el programa de mano de la muestra donde expresaba su profundo compromiso personal con la temática que les ocupaba. Todos ellos consideraban que el arte había de ocuparse de la realidad española del momento y pretendían comunicar de forma efectiva la verdad escamoteada por el régimen a toda la sociedad. Esta intención social condicionaba los demás aspectos de su obra, desde una estética que se calificaba de realista, hasta la técnica de realización: el grabado. En 1969 esta exposición era recordada por José María Moreno Galván como la primera piedra en el desarrollo de las iniciativas críticas colectivas.

En 1957 José García Ortega expuso de nuevo en la sala Alfil, esta vez en solitario. En dicha ocasión el artista presentó una Declaración de Principios, un escrito donde proponía un realismo caracterizado por la selección temática y la apuesta por la figuración. Su objetivo era proporcionar "una realidad interpretada, enjuiciada por el artista y proyectada hacia una mejor comprensión de la vida y del hombre como ser social" (García, 1957, citado en Martínez, 1992, pág. 59). A pesar de su militancia en el PCE el artista no realizó su labor de "captación" de artistas contra la dictadura a través de un discurso en el que se impusiera una estética como la del realismo socialista. Apelaba a unas inquietudes, a unos principios ideológicos y éticos compartidos, lo cual era una sabia medida para lograr aglutinar en un solo grupo al mayor número posible de artistas antifranquistas, evitando el rechazo que podía ocasionar una mención explícita al comunismo. Quizá habría que ver en el fondo de todo esto una aplicación, en el campo plástico, de la política de reconciliación nacional promovida por el PCE a mediados de la década de los cincuenta.

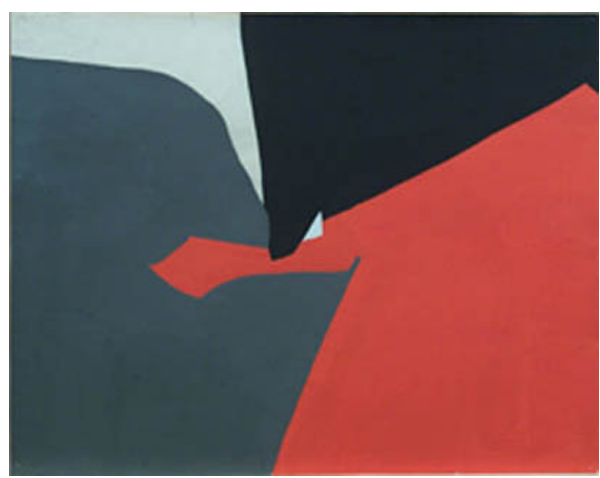

Figura 2. Equipo 57, Sin título, 1957 
En ese mismo año, que era también en el que había nacido el grupo El Paso, se formó el Equipo 57 en París. Éste era el resultado de la colaboración entre Ángel Duarte, Agustín Ibarrola, Juan Serrano y José Duarte, que se conocieron ganándose la vida como podían con tal de poder estar en la capital francesa, atentos al pulso artístico internacional. En lo que se considera su manifiesto fundacional, que presentaba la exposición que celebraron en el Café Le Rond Point de París en 1957, estos artistas hablaban de la obra de arte como "una solución política" y denunciaban al informalismo como arte burgués, individualista y destructivo. Consideraban que era necesario hacer una revolución estética pero también social por medio del arte, denunciaban la corrupción del sistema de galerías, concursos, críticos, organismos internacionales, etc., y hacían un llamamiento "a todos los que sientan la necesidad de una solución colectiva como base de la suya propia" (Equipo 57, 1957, citado en González, 1993, pág. 115). La expresión individual, interior, lo espiritual y lo inefable de la abstracción informalista eran sustituidas por la racionalidad de un trabajo colectivo que volvía a los rasgos revolucionarios de las vanguardias en lo estético pero también en lo social y lo político. Los referentes de su propuesta abstracta y geométrica se encontraban en el arte de Jorge Oteiza -figura absolutamente determinante en el desarrollo de su trabajo- y en iniciativas artísticas de vanguardia como el suprematismo, el neoplasticismo o la Bauhaus (Fig. 2). Las preocupaciones sociales eran acuciantes para todos ellos y, además, se veían reforzadas por el papel de militancia activa dentro del PCE de algunos de los componentes del Equipo 57, como Agustín Ibarrola y José Duarte. En este mismo sentido estético y también de compromiso social y plástico desde la abstracción geométrica se estaba desarrollando también el trabajo de artistas como Manuel Calvo, el Equipo Córdoba o algunos miembros del Grupo Parpalló.

En un principio la crítica de arte más avanzada dedicó su atención y sus comentarios positivos a ambas tendencias abstractas, geométrica e informalista. No obstante, a medida que se acercaba el final de la década, las posiciones se radicalizaron y ambas corrientes se convirtieron en antagónicas tanto a ojos de los artistas como de la crítica. Fue el caso de Vicente Aguilera Cerni, que había formado parte de las iniciativas más avanzadas del momento -era uno de los firmantes del primer manifiesto de El Paso y era miembro fundador del Grupo Parpalló-, y que publicaba en 1959 su texto "El arte además" en el que defendía el compromiso ético del arte. El apoyo decidido a un arte social se dio también en los escritos de José María Moreno Galván y de Antonio Giménez Pericás. Las contribuciones del primero sobre el informalismo en Acento Cultural (Moreno, 1958 y 1959) dieron paso a textos sobre el arte geométrico del Equipo 57 (Moreno, 1960). En paralelo - lo cual da idea de la posición que adoptaría el régimen ante tales interpretaciones comprometidas de la obra geométrica abstracta-, Giménez Pericás fue censurado en su intervención en el ciclo de conferencias organizado en el Club Urbis con motivo de la exposición del Equipo 57 en marzo de 1959 "dado el cariz político que (...) tomaron los acontecimientos" (Llorente, 1982). La participación de estos tres críticos en las actividades de estas agrupaciones fue fundamental para su desarrollo futuro. Todos tomaron parte en varias conferencias y debates en torno al fenómeno de la abstracción celebrados en 1959, en ellos la oposición entre las corrientes informalistas y formalistas llegó incluso a la prensa. Fue el caso de los coloquios que tuvieron lugar en la Primera decena de problemas esté- 
ticos actuales, celebrados en la Sala Darro, dirigida por Moreno Galván, o también de los celebrados en el Club Universitario de Valencia con motivo de la exposición de Manuel Calvo (Barreiro, 2009). Además, allí coincidieron los artistas que, poco después, serían agrupados por Vicente Aguilera Cerni bajo la denominación de Arte Normativo en un intento de crear un frente común contra el informalismo.

En la primavera de 1959 las valoraciones negativas del informalismo por parte de un sector de la crítica arreciaron al considerarse que se había convertido en la imagen propagandística del franquismo. En esas fechas se celebró la exposición 13 Peintres Espagnols Actuels en el Museo de Artes Decorativas de París, Antoni Tàpies, representado en la muestra, decidió retirarse de la misma al advertir el cariz propagandístico de la exposición. Antonio Saura se solidarizó con él y decidió no participar en más exposiciones organizadas por el régimen. Al poco tiempo, Millares también expresaba su intención de desvincularse de la esfera oficial por los mismos motivos políticos (Millares, 1959, citado en Nieto, 2001, pág. 14). Al hilo de dicha exposición, la revista comunista Nuestras Ideas publicó un artículo en el que denunciaba el uso político que hacía el régimen del informalismo y afirmaba la incapacidad de este último para hacerse cargo de los problemas de la sociedad así como su fácil recurrir a los tópicos de lo español, junto con todo ello se señalaba que sus propuestas eran sintomáticas de la falsedad y las contradicciones en las que se debatía el artista en esos momentos (García, 1959). Este escrito suscitó una respuesta en El Socialista que fue reproducida en Nuestras Ideas (Bruno, 1960) junto a la respuesta de Pascual García (1960) y a una invitación al debate que no tuvo demasiado éxito. Ante la aparente falta de nuevos escritos, Nuestras Ideas publicó un texto de José Navarro (1960) sobre las artes en la Unión Soviética para aclarar una serie de cuestiones en torno al realismo socialista. Esto último es significativo puesto que tiene que ver con la introducción de un elemento más en la discusión plástica, el de un realismo que había dado sus primeros pasos unos años atrás y que no tardaría en afirmarse en el panorama estético español.

\section{La figuración se extiende}

Finalmente las labores de José Ortega para formar un grupo decididamente antifranquista dieron fruto. A finales de 1959, en un bar de la calle Modesto Lafuente de Madrid, se dieron cita José García Ortega, Ricardo Zamorano, Dimitri Papagueorguiu, Luis Garrido, Antonio Valdivieso, Javier Clavo, Pascual Palacios Tárdez, Manuel Ortiz Valiente y Antonio Zarco. Era la reunión fundacional de Estampa Popular. Como he analizado con detalle en recientes publicaciones (Haro, 2010b) esta iniciativa no tardaría en extenderse por España-llegaría a tener núcleos en Córdoba, Sevilla, Vizcaya, diversas localidades de Cataluña, Valencia y Galicia-, y configuraría una red con la que estuvieron vinculados, de una manera u otra, la práctica totalidad de los artistas comprometidos contra la dictadura.

Si bien se presentaba el trabajo en exposiciones colectivas, cada artista firmaba su propia obra. Se optaba preferentemente por la técnica del grabado -aunque no era la única empleada por los artistas de los grupos- porque esto permitía hacer una obra múltiple que era más barata y podía resultar asequible para un mayor número de per- 
sonas. El hecho de querer hacer obras que estuvieran al alcance de todos no sólo en los aspectos económicos sino también en lo concerniente a su interpretación, planteó el problema de qué características había de revestir una obra para ser inteligible para muchos. La respuesta mayoritaria a esta cuestión -si bien no la única- fue la de una figuración que se plasmaba en propuestas de los más diversos tipos. Conviene aclarar que, a pesar del tópico existente acerca del realismo social de corte comunista de Estampa Popular, en su seno nunca se impuso el "realismo socialista" del que se hablaba en Nuestras Ideas o sobre el que había escrito Ortega. Aunque en algunos casos se hablaba explícitamente de "realismo", no había condiciones estéticas que cumplir para formar parte de Estampa Popular; este realismo consistía, más bien, en concebir la obra ligada a la realidad y al contexto más inmediato. En recientes publicaciones he mostrado cómo el gran acierto de Ortega en su labor como aglutinador de artistas antifranquistas fue precisamente el de no imponer estética alguna, uniendo a los artistas en torno a una intención común (Haro, 2010a y b).

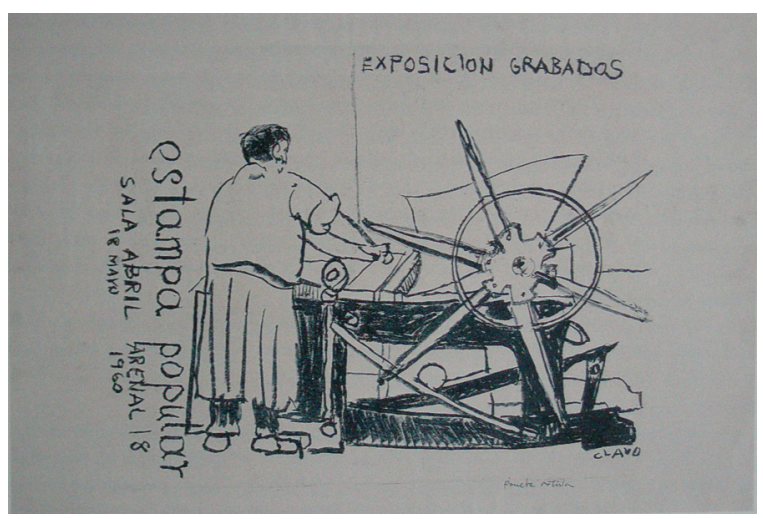

Figura 3. Javier Clavo, cartel de la exposición de Estampa Popular en la galería Abril, mayo de 1960

La primera exposición de Estampa Popular tuvo lugar en la galería Abril, en mayo de 1960 (Fig.3). Al mismo tiempo el Equipo 57 inauguraba una muestra en la galería Darro y lanzaba un manifiesto en el que, al igual que Estampa Popular, criticaba el arte como objeto de mercado y decía que el producto de la investigación plástica había de formar parte de los objetos de uso diario. Mientras no se dieran las condiciones que permitieran que las artes plásticas se integraran en la vida material a través del diseño y del urbanismo, los miembros del Equipo proponían vender sus obras a precio de coste, para que estuvieran al alcance de todo el mundo (Equipo 57, 1960). De hecho, el número 8 de Acento Cultural en el que se publicaba dicho texto estaba dedicado casi por completo al Equipo 57 ya que, tal y como se explicaba en la propia revista, se consideraba necesario dar a conocer otras propuestas para contrarrestar la atención prestada al informalismo, al que se acusaba de recibir el apoyo oficial. Al parecer los miembros del Equipo 57 visitaron la exposición de Estampa Popular -no en vano, varios de ellos eran militantes del PCE- pero, entonces, criticaron la obra figurativa propuesta por estos últimos (Zamorano, 2006 y 1976, este último citado en Rodríguez, 1976, págs. 212-226). 


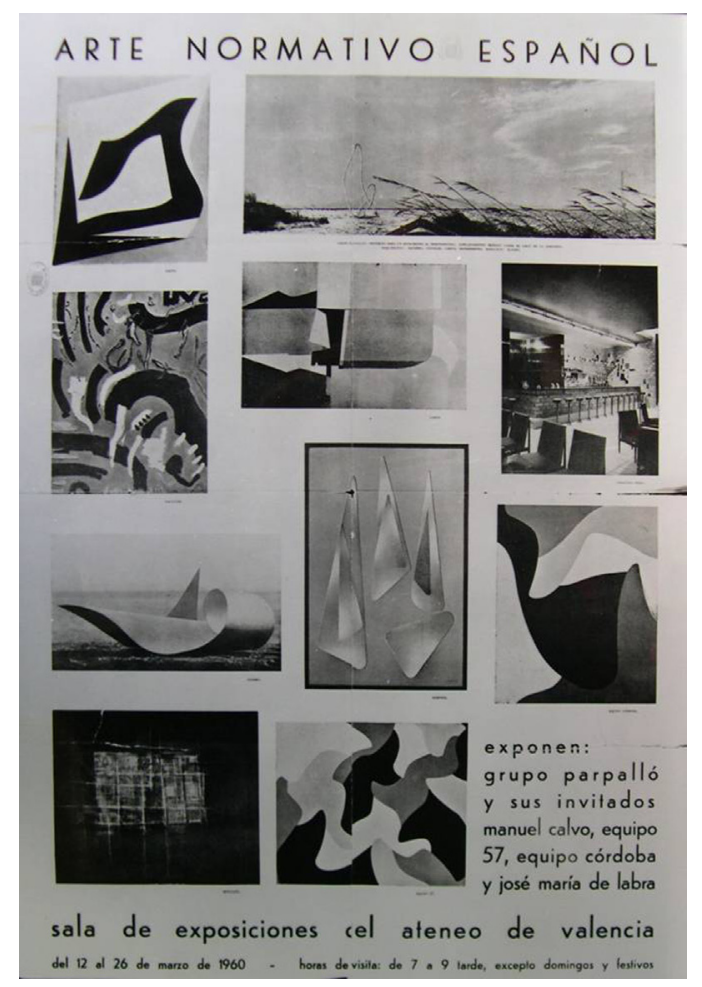

Figura 4. Cartel de la I Exposición Conjunta de Arte Normativo Español, Ateneo Mercantil de Valencia, marzo de 1960.

Unos meses antes, en marzo de 1960, había tenido lugar la I Exposición Conjunta de Arte Normativo Español, celebrada en el Ateneo Mercantil de Valencia (Fig. 4). La muestra había sido organizada por Aguilera Cerni con la intención de aglutinar a todos los representantes de la abstracción geométrica española. De hecho, en noviembre de 1960 el crítico publicó un artículo en Cuadernos de Arte y Pensamiento en el que trataba de proporcionar las bases teóricas de dicho frente común que se posicionaba, explícitamente, contra el informalismo. Allí hacía un llamamiento a todos aquellos que tuvieran conciencia ética de sus actividades "artísticas" para que se unieran bajo el paraguas del "Arte Normativo" (Aguilera, 1960, pág. 55). Sin embargo, los artistas mencionados por Aguilera Cerni en su escrito-llamada no se sintieron bien representados por sus palabras por lo que el intento de crear dicho frente común geométrico fracasó. No ocurrió así con el espíritu de comunicación y de transformación de la sociedad que les animaba. Las dificultades que presentaba comunicar con la sociedad a través de obras abstractas cuando no se tenían los medios para llevar a cabo una producción en serie o para intervenir en el espacio público, unidas a la militancia política condujeron a la mayoría de estos artistas geométricos a colaborar con Estampa Popular en los años siguientes, contribuyendo significativamente a consolidar una red y un frente plástico antifranquista de ámbito nacional. 
Esto sucedió también en las filas de los informalistas: El Paso, que venía cosechando éxitos desde finales de la década anterior, se disolvió en 1960. Poco después, en 1961, Saura y Millares publicaron unos artículos en Acento Cultural donde defendían el compromiso y la sinceridad de sus propuestas plásticas, donde hablaban de protesta y de un arte que se dirigiera a la sociedad, despreciando todo arte matérico vacío y decorativo (Saura, 1961; Millares, 1961). Gracias a su participación en exposiciones internacionales con el apoyo oficial, estos artistas habían conseguido exponer con éxito fuera de España. Una vez que habían salido al mercado internacional, les resultaba mucho más fácil oponerse al régimen puesto que contaban con cierta independencia. En consonancia con las inquietudes expresadas en el artículo citado, también Antonio Saura colaboró con su obra a las exposiciones de Estampa Popular (Fig.5)
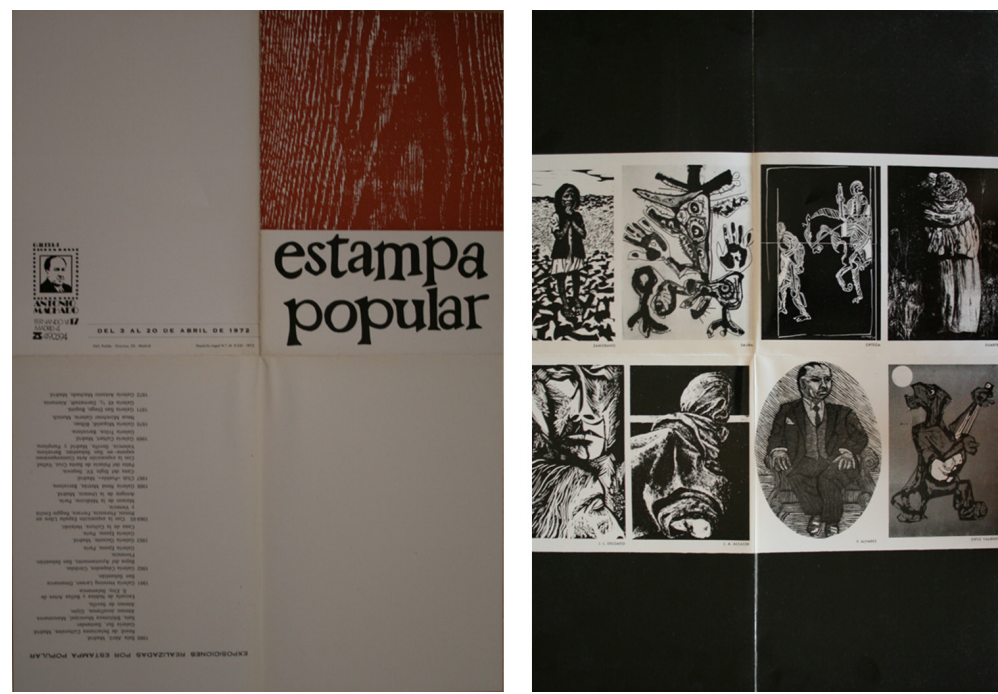

Figura 5. Dos caras del desplegable de la exposición de Estampa Popular en la galería Antonio Machado de Madrid, 3-20 de abril de 1972.

Lo que se ha juzgado como una regresión en la trayectoria de los artistas abstractos que se sumaron a una propuesta figurativa colectiva como la de Estampa Popular, habría de interpretarse como una transformación dentro de un frente común antifranquista que se modificaba para adaptarse de la mejor manera posible a su entorno cultural, social y político. Por consiguiente, como ya he expuesto en otro lugar (Haro, 2010a) una apuesta figurativa como ésta ha de entenderse dentro de un movimiento social de protesta, no como meras disonancias en un relato evolutivo del arte español contemporáneo. La apuesta plástica figurativa se revela así como un elemento fundamental en la constitución del marco cultural del movimiento antifranquista, tal y como se ha empleado este término en estudios clásicos sobre movimientos sociales (Tarrow, 1998). Un marco que contribuyó definitivamente a dar cohesión y sentido a una iniciativa de la que formaban parte personas de perfiles muy diversos que lograron luchar juntas contra la dictadura franquista. 


\section{Referencias}

Aguilera, V. (1959). El arte además. Índice de las Artes y las Letras, 122 a 129, Madrid, 12-13, 13-14, 16, 16 y 25, 14, 14, respectivamente.

Aguilera, V. (1960). Arte normativo español. Primera pancarta para un movimiento, Cuadernos de arte y pensamiento, 4, Madrid, 43-55.

Ainaud, J., Roig, A., Areán, C.A., Castro, J. de, Cirlot, J.E., Gaya, J. A., et al. (1961). La pintura informalista en España a través de los críticos. Madrid: Dirección General de Relaciones Culturales.

Barreiro, P. (2009). La abstracción geométrica en España (1957-1969). Madrid: CSIC.

Bruno (1960). A propósito de una crítica. Nuestras Ideas, 8, Bruselas, 45-47.

Cabañas, M. (1995). El ocaso de la política artística americanista del franquismo. Toluca: Instituto Mexiquense.

Cabañas, M. (1996a). Politica artística del franquismo: el hito de la Bienal Hispanoamericana de Arte. Madrid: CSIC.

Cabañas, M. (1996b). Postrimerías de un instrumento de la política artística del franquismo. El final de las Bienales Hispanoamericanas de Arte. Boletín del Seminario de Estudios de Arte y Arqueología, LXII, Valladolid, 497-519.

Calvo, F. (coord.) (1985). España. Medio siglo de arte de vanguardia: 1939-1985. Madrid: Fundación Santillana, Ministerio de Cultura.

Díaz, J. (1998). La "oficialización" de la vanguardia artística en la postguerra española el informalismo en la crítica de arte y los grandes relatos. Tesis doctoral inédita. Cuenca: Universidad de Castilla La-Mancha.

Díaz, J. (2000). El triunfo del informalismo. La consideración de la pintura abstracta en la época de Franco. Madrid: Metáforas del Movimiento Moderno.

Domínguez, E. (1990). Introducción al problema de las conductas estéticas durante el franquismo (1, 1939-1960). Arte, individuo y sociedad, 3, Madrid, 17-97.

Equipo 57. (1960). Idea y plan. Acento Cultural, 8, 58-61.

García, P. (1959). A propósito de una exposición. Nuestras Ideas, 7, Bruselas, 108111.

García, P. (1960). A propósito de la crítica de una crítica. Nuestras Ideas, 8, Bruselas, 48-51.

González, M. (comis.) (1993). Equipo 57 (catálogo de exposición), Madrid, MNCARS.

Haro, N. de. (2010a). Estampa Popular: una actividad política antifranquista. En S. Espinós y R. Gallego (coords.): ¿La guerra ha terminado? Arte en un mundo dividido (1945-1968) (págs. 155-168). Madrid: MNCARS.

Haro, N. de. (2010b). Grabadores contra el franquismo. Madrid: CSIC.

Llorente, A. (1982). El Equipo 57 y el arte normativo español. Memoria de licenciatura inédita. Universidad de Valladolid.

Martínez, A. (1992). Aspectos estéticos y sociales de Estampa Popular. Tesis doctoral inédita, Salamanca: Universidad de Salamanca.

Millares, M. (1961). Destrucción-construcción en mi pintura. Acento Cultural, 12-13 (extraordinario), Valencia, 75. 
Moreno, J.M. (1958). El informalismo en la pintura I. Acento Cultural, 2, Madrid, 35-38.

Moreno, J.M. (1959). El informalismo en la pintura II. Acento Cultural, 3, Madrid, enero de 1959, 36-39.

Moreno, J.M. (1960). El Equipo 57. Acento Cultural, 8, Madrid, 46-49.

Moreno, J.M. (1969). La última vanguardia. Barcelona: Magius.

Navarro, J. (1960). Las artes plásticas en su tiempo y su lugar. Nuestras Ideas, 9, $62-73$.

Nieto, V. (comis.) (2001). Canogar. Cincuenta años de pintura (catálogo de la exposición). Madrid: MNCARS.

Rodríguez, M.P.C. (1976). Aproximación a la pintura realista de la posguerra, la Estampa Popular. Memoria de licenciatura inédita. Universidad Complutense de Madrid.

Ruiz, J. (1952). Arte y política. Cuadernos Hispanoamericanos, 26, 162-165.

Saura, A. (1961). Carta abierta. Acento Cultural, 12-13 (extraordinario), Valencia, 76-79.

Tarrow, S. (1998). Power in Movement. Cambridge: Cambridge University Press.

Zamorano, R. (2006). Declaraciones en entrevista con la autora el 7 de enero de 2006. 